\title{
A Role for Decorin in the Structural Organization of Periodontal Ligament
}

\author{
Lari Häkkinen, Silke Strassburger, Veli-Matti Kähäri, Paul G. Scott, Inge Eichstetter, \\ Renato V. lozzo, and Hannu Larjava
}

Department of Oral Biological and Medical Sciences (LH, SS, HL), Faculty of Dentistry, University of British Columbia, Vancouver, British Columbia, Canada; Department of Medical Biochemistry and Dermatology (V-MK), Centre for Biotechnology, University of Turku, Turku, Finland; Department of Biochemistry (PGS), University of Alberta, Edmonton, Alberta, Canada; and Department of Pathology, Anatomy, and Cell Biology and the Kimmel Cancer Center (IE, RVI), Thomas Jefferson University, Philadelphia, Pennsylvania

SUMMARY: Decorin is a small leucine-rich proteoglycan that interacts with several matrix molecules, including various types of collagen and growth factors, and suppresses the growth of neoplastic cells by an epidermal growth factor (EGF) receptor-mediated pathway. Decorin is abundantly expressed in the periodontal connective tissues during development and tissue maintenance. In periodontal disease, which is one of the most common diseases in the human kind, the level of decorin is decreased in the periodontal connective tissue. Abnormal expression of decorin may also associate with certain inherited disorders that involve increased susceptibility to severe periodontal disease in the early childhood. Therefore, we investigated the periodontal tissues of mice with targeted disruption of the decorin gene. Gross and microscopic analyses showed that decorin-deficient mice appeared to have normal tooth development and eruption, and there were no signs of periodontal disease. However, electron microscopic analysis revealed abnormal morphology and organization of the collagen fibrils in the periodontal ligament. The number of periodontal ligament fibroblasts in the decorin-deficient mice was also increased about two-fold as compared with the wild-type mice. In cell culture, ectopic overexpression of decorin in NIH 3T3 fibroblasts or decorin added exogenously to periodontal fibroblasts suppressed cell growth. However, blocking the EGF receptor tyrosine kinase activity did not prevent the decorin-elicited growth suppression in periodontal fibroblasts. Additionally, decorin did not induce a marked increase in the relative expression of p21 mRNA in periodontal fibroblasts. Therefore, decorin appeared to regulate growth of normal periodontal fibroblasts by a mechanism distinct from that reported for neoplastic cells. The findings demonstrate that decorin plays a role in the organization of collagen fibrils and regulates cell proliferation in the periodontal ligament. (Lab Invest 2000, 80:1869-1880).

P eriodontal diseases comprise a group of infections that lead to irreversible loss of tissue support around the teeth. The advanced forms of periodontal disease affect more than $10 \%$ of adults and more than $30 \%$ of people 55 to 64 years of age (Brown and Loe, 1993). The disease can be advanced before any pain or symptoms are experienced and often leads to tooth loss. The microbes and inflammatory processes associated with periodontal disease may also affect the severity of systemic diseases (Beck et al, 1999). Different individuals show considerable differences in susceptibility to and in the severity of periodontal disease (Page, 1999). There are indications that more than half of the increased susceptibility to periodontal disease may depend on genetic factors

Received July 27, 2000.

The study was funded by Academy of Finland (LH), Finnish Cultural Foundation (LH), German Academic Exchange Service (SS), NIH CA39481 (RVI), MRC MT-15055 (HL), and MRC 11768 (PGS).

Address reprint requests to: Dr. Lari Häkkinen, University of British Columbia, Faculty of Dentistry, Department of Oral Biological and Medical Sciences, 2199 Wesbrook Mall, Vancouver, B.C. Canada V6T $1 Z 3$. E-mail:Lhakkine@interchange.ubc.ca
(Page, 1999). However, to date, only a few molecular traits that associate with increased susceptibility to periodontal disease have been identified (Hart et al, 2000).

Proteoglycans comprise a class of intracellular, cell membrane-associated, and extracellular matrix molecules that regulate cell function and growth, activity of growth factors and proteases, and assembly of the extracellular matrix (lozzo, 1998). Small leucine-rich proteoglycans (SLRPs) form a family of genetically distinct, but structurally related, extracellular matrix molecules. Among SLRPs, decorin may play an important biological role through its ability to interact with the fibrillar proteins in the connective tissue matrix, including collagen, fibronectin, and fibrillin (lozzo, 1999; Trask et al, 2000). This is evidenced by findings that decorin inhibits collagen fibril formation in vitro (Vogel et al, 1984) and that targeted disruption of the decorin gene leads to disorganized collagen fibril formation and skin fragility in mice (Danielson et al, 1997). Because of its ability to bind and inactivate transforming growth factor- $\beta$ (TGF- $\beta$ ), decorin has been used to prevent experimental renal and lung fibrosis that is associated with increased expression 

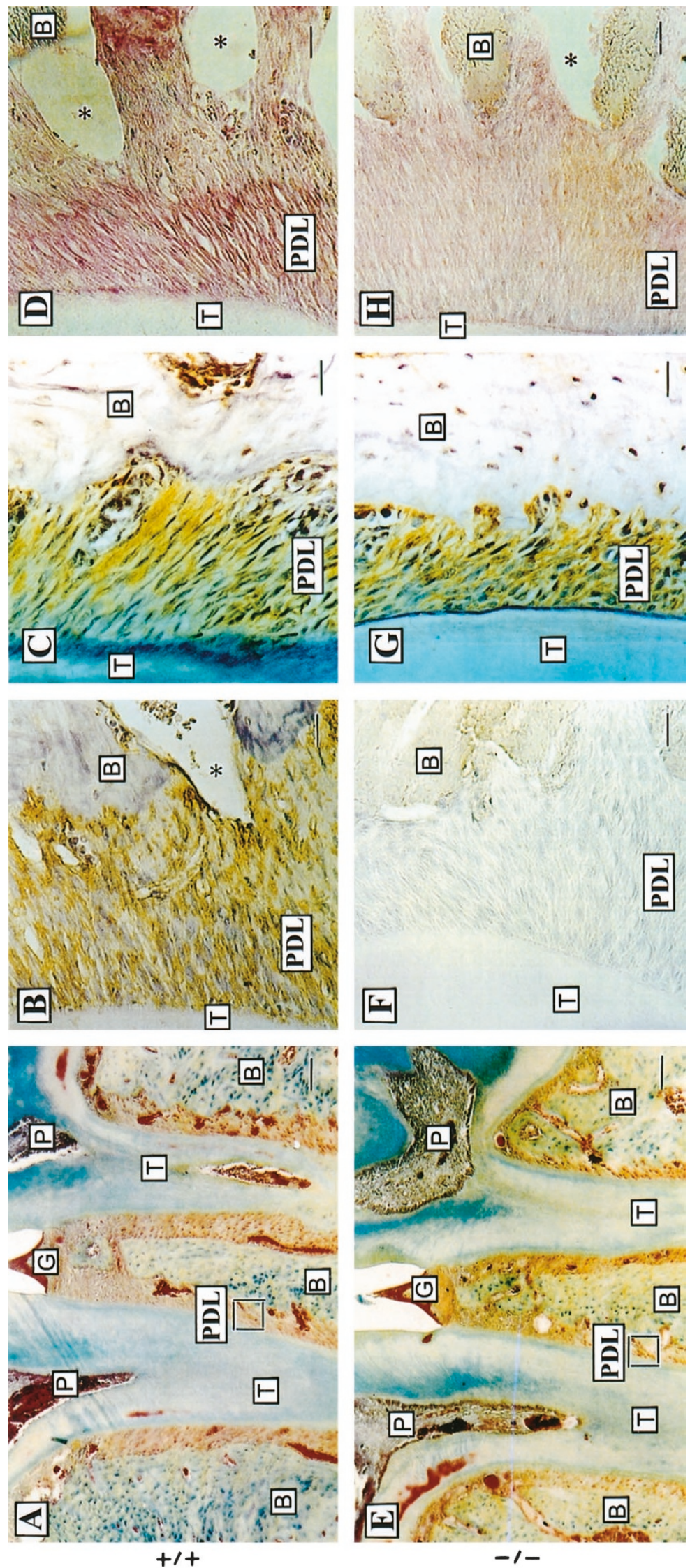

Figure 1. 
and activation of TGF- $\beta$ (Border et al, 1992; Giri et al, 1997). Furthermore, decorin is able to suppress the malignant phenotype of several cancer cell types by binding and activating epidermal growth factor receptor-mediated signaling pathways, leading to subsequent growth arrest of the cells (De Luca et al, 1996; lozzo et al, 1999; Moscatello et al, 1998; Santra et al, 1995).

Decorin is one of the major proteoglycans secreted by human periodontal fibroblasts in vitro (Häkkinen et al, 1996; Larjava et al, 1992), and it is expressed abundantly in the periodontal connective tissues in vivo (Cheng et al, 1999a; Häkkinen et al, 1993; Oksala et al, 1995, 1997; Robey, 1996). During development of teeth in rats, expression of decorin is spatially and temporally regulated (Zhang et al, 1995), suggesting that it may regulate odontogenesis and formation of the periodontal ligament. It is possible that deficient expression and/or function of decorin may be involved in the evolution of developmental disorders in the periodontal tissues and in the pathogenesis of periodontal disease. This hypothesis is supported by findings that in growth hormone-deficient rats delayed and disturbed development of teeth and jaws is associated with decreased expression of decorin (Zhang et al, 1995). Deficient decorin expression by fibroblasts has also been reported in certain inherited disorders, including osteogenesis imperfecta, infantile progeroid syndrome, and in Ehlers-Danlos syndrome (EDS) (Beavan et al, 1993; Fedarko et al, 1992; Fushimi et al, 1989). In addition to several systemic defects, patients suffering from osteogenesis imperfecta, infantile progeroid syndrome, or EDS types I and VIII also have abnormalities in development and eruption of teeth (Pope et al, 1992; Yu and Zeng, 1991). Although the genetic backgrounds of these conditions are different and partially unknown, they all involve abnormal development and organization of collagen, suggesting that aberrant deposition and/or function of decorin may contribute to the outcome of the disease. Furthermore, EDS type VIII patients are susceptible to severe periodontal disease in early childhood (Hartsfield and Kousseff, 1990; Nelson and Bartold, 1998; Pope et al, 1992). Early onset periodontitis has also been reported in EDS types IV, VII, and IX (Aldred and Bartold, 1998; Hartsfield and Kousseff, 1990; Ooshima et al, 1990). In periodontal disease, the breakdown of the collagen-rich connective tissue matrix parallels a decrease in the level of decorin in the inflamed connective tissue (Oksala et al, 1997). The decrease in decorin expression most likely results from increased decorin degradation caused by inflammation (Waddington et al, 1998) and down-regulation of decorin expression of fibroblasts by inflammatory cytokines (Häkkinen et al, 1996; Kähäri et al, 1991; Mauviel et al, 1995) and mitogenic growth factors (Laine et al, 2000). Therefore, it is possible that aberrant decorin expression may predispose to inflammatory tissue breakdown and periodontal disease. In the present study, we have examined mice with targeted disruption of the decorin gene to investigate the functional role of decorin in the formation and maintenance of periodontal tissues.

\section{Results}

\section{Abnormal Collagen Morphology in the Periodontal Ligament of the Decorin-Deficient Mice}

Morphological and histological analysis showed that the jaws and teeth of the decorin -/- mice developed normally and that there were no gross morphological differences in the dental and periodontal tissues in the wild-type mice (Fig. 1A) compared with those tissues in the decorin -/- (Fig. 1E) mice. The periodontal tissues appeared healthy, and there was no inflammation or signs of periodontal disease. To confirm the absence of decorin in the decorin gene knock-out mice, we performed immunohistochemical staining using the antidecorin antibody. In the wild-type mice, decorin was expressed abundantly throughout the periodontal ligament (Fig. 1B). Decorin was also expressed in the subepithelial connective tissue of gingiva and oral mucosa, in the dental pulp, and in predentin of molars and incisors (not shown). In contrast, the decorin -/- mice showed complete lack of immunostaining for decorin in the periodontal ligament (Fig. 1F) and in the other oral and dental tissues examined (not shown). Both decorin -/- mice and wild-type mice showed identical immunoreactivity and localization for biglycan in the periodontal ligament (Fig. 1, C and G) and in other oral and dental tissues examined (not shown). Analysis by using immunohistochemical staining of type I collagen showed a more diffuse staining pattern of collagen in the periodontal ligament of the decorin -/- mice (Fig. 1H) compared with the wild-type mice (Fig. 1D). A closer examination using electron microscopy showed that collagen fibers in the decorin -/- mice were heterogeneous in size and irregularly shaped, resembling abnormal lateral fusion of the fibrils (Fig. 2, C and D). In addition to many relatively large-diameter collagen fibers, there

\footnotetext{
Figure 1.

Representative histological appearance of the periodontal tissues $(A$ and $E)$ and expression of decorin $(B$ and $F)$, biglycan $(C$ and $G)$, and type $I$ collagen $(D$ and $H)$ in the wild-type $(A$ to $D)$ and decorin $-/(E$ to $H)$ mice molar teeth. $A$ and $E$, In the wild-type $(A)$ and decorin -/-mice $(E)$, the teeth are fully developed and erupted, and the periodontal tissues are ultrastructurally similar. $B$ and $F$, In the wild-type mice $(B)$, decorin is abundantly expressed throughout the periodontal ligament and colocalizes with the collagen fibers. There is no immunoreactivity for decorin in the periodontal ligament of the decorin knock-out mice $(F)$. $C$ and $G$, In the wild-type $(C)$ and decorin $-/(G)$ mouse periodontal ligament, biglycan shows identical staining intensity and localizes on the collagen fibers in the extracellular matrix of the periodontal ligament. $D$ and $H$, In the wild-type mice $(D)$, collagen fibers are homogeneous in diameter and well organized to parallel orientation. In the decorin -/mice $(H)$ collagen fibers are poorly organized and show a more diffuse type I collagen localization compared with the wild-type mice. B, bone; T, tooth; PDL, periodontal ligament; $G$, gingiva; ${ }^{*}$ artifact caused by tissue shrinkage. The rectangular area shows the localization of the higher magnification panels $(B, C, D, F, G$ and $H$ ) with respect to corresponding periodontal tissues. $A$ and $E$, bar $=200 \mu \mathrm{m} ; B, C, D, F, G$, and $H$, bar $=50 \mu \mathrm{m}$. $A$ and $E$, Movat staining; $B, C, D, F, G$, and $H$, hematoxylin counterstaining.
} 
were also very small-diameter fibrillar structures, indicating the presence of isolated very small-diameter collagen fibrils in the periodontal ligament of the decorin -/- mice (Fig. 2D). In these mice (Fig. 2, C and D), collagen orientation was unorganized and the interfibrillar spaces were wider compared with the wild-type mice (Fig. 2, A and B). In the wild-type mice, the collagen fibers were homogeneous in size and shape, the fibers were arranged in parallel orientation, and there were no small-diameter collagen fibrils isolated from larger-diameter collagen fibers (Fig. 2, A and $\mathrm{B})$.

\section{Hypercellularity of the Periodontal Ligament in the Absence of Decorin}

A closer histological examination of the periodontal tissues of decorin -/- mice indicated also that the periodontal ligament of their molar teeth was hypercellular (Fig. 3, A and B). Therefore, we compared the number of cells with spindle-shaped morphology in the mid-third area of the periodontal ligament in the mandibular molars of the decorin -/- and wild-type mice by using histomorphometrical analysis. The findings from pooled data from tissue sections from five decorin -/- mice and five wild-type mice showed that the mean number of fibroblasts in the molar periodontal ligament of decorin -/- mice was increased 1.9-fold ( $p<0.0001$, Student's $t$ test) as compared with the wild-type mice (Fig. 3C).

\section{Decorin Suppresses Growth of Periodontal Fibroblasts}

Previous findings have shown that decorin can suppress the cell growth of neoplastic cells (Moscatello et al, 1998; Santra et al, 1997). To test whether decorin can inhibit the growth of normal fibroblasts, we stably transfected mouse NIH 3T3 fibroblasts with full-length human decorin cDNA. Four 3T3 cell clones, which were overexpressing 3- to 32-fold-increased amounts of decorin mRNA compared with those cells transfected with the vector alone, were used to analyze cell growth (Fig. 4A). Clones DCN1, DCN2, and DCN3, which had highest decorin expression (13-, 32-, and 20 -fold-increased expression compared with the vector transfected cells, respectively), ceased to grow in
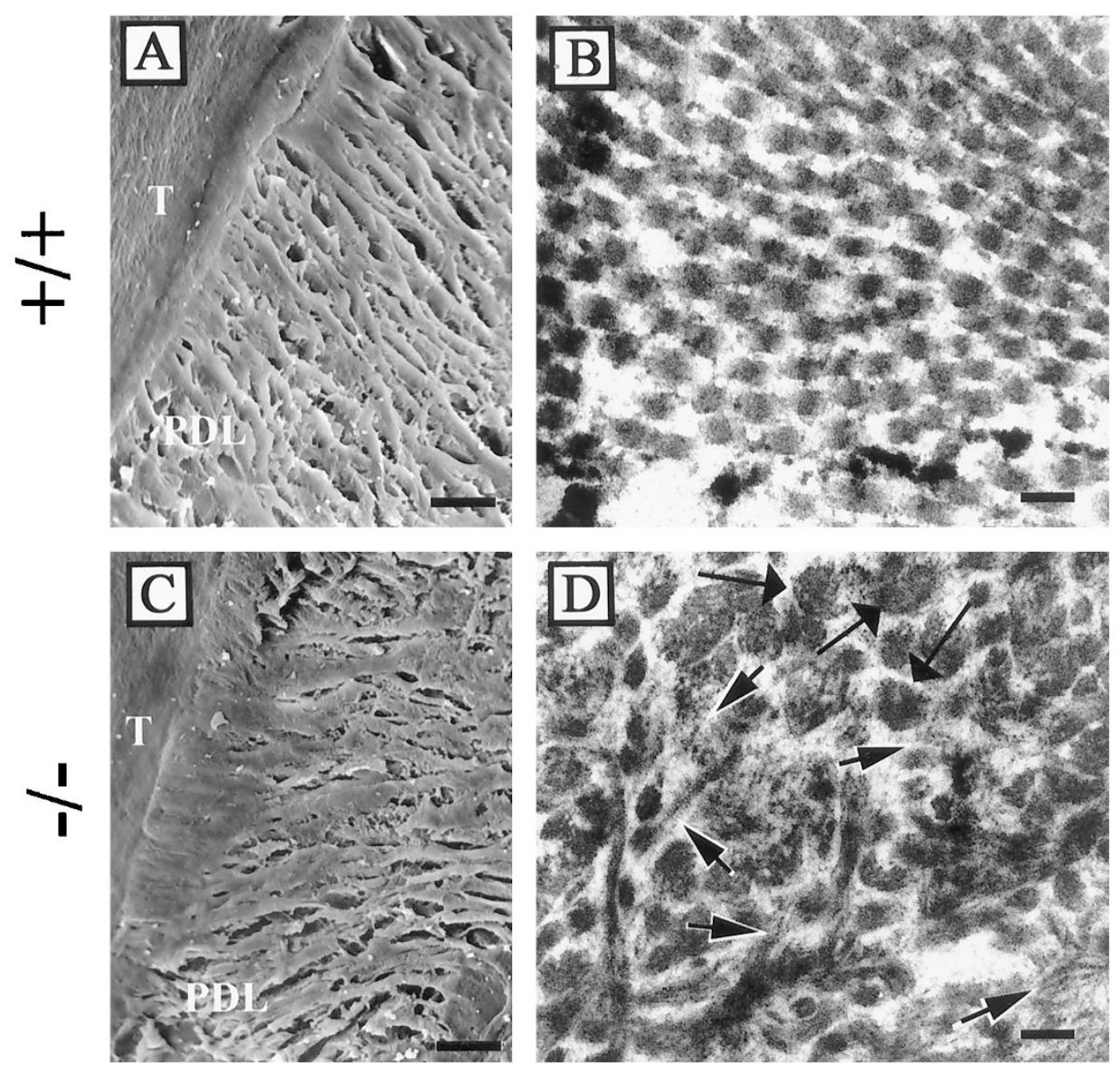

Figure 2.

Electron microscopic analysis of collagen organization in the periodontal ligament. $A$ and $C$, Scanning electron micrographs of collagen fibers in the wild-type $(A)$ and decorin -/- mouse $(C)$ molar periodontal ligament. In the decorin -/- mouse, collagen fibers are wider in diameter and more randomly arranged compared with the wild-type mouse. $B$ and $D$, Transmission electron micrographs of collagen fibers in the wild-type $(B)$ and decorin $-/$ - mouse $(D)$ periodontal ligament. In the decorin -/- mouse, collagen fibers are more randomly arranged and irregularly shaped, and show more heterogeneity in the cross-sectional size compared with the wild-type mouse. In the decorin $-/$ - mouse periodontal ligament, there are very large-diameter collagen fibers $(D$, long arrows) and also many very small-sized collagen fibrils separated from the larger collagen fibers $(D$, short arrows). PDL, Periodontal ligament; T, tooth. $A$ and $C$, bar $=0.2 \mu \mathrm{m} ; B$ and $D$, bar $=0.1 \mu \mathrm{m}$. 

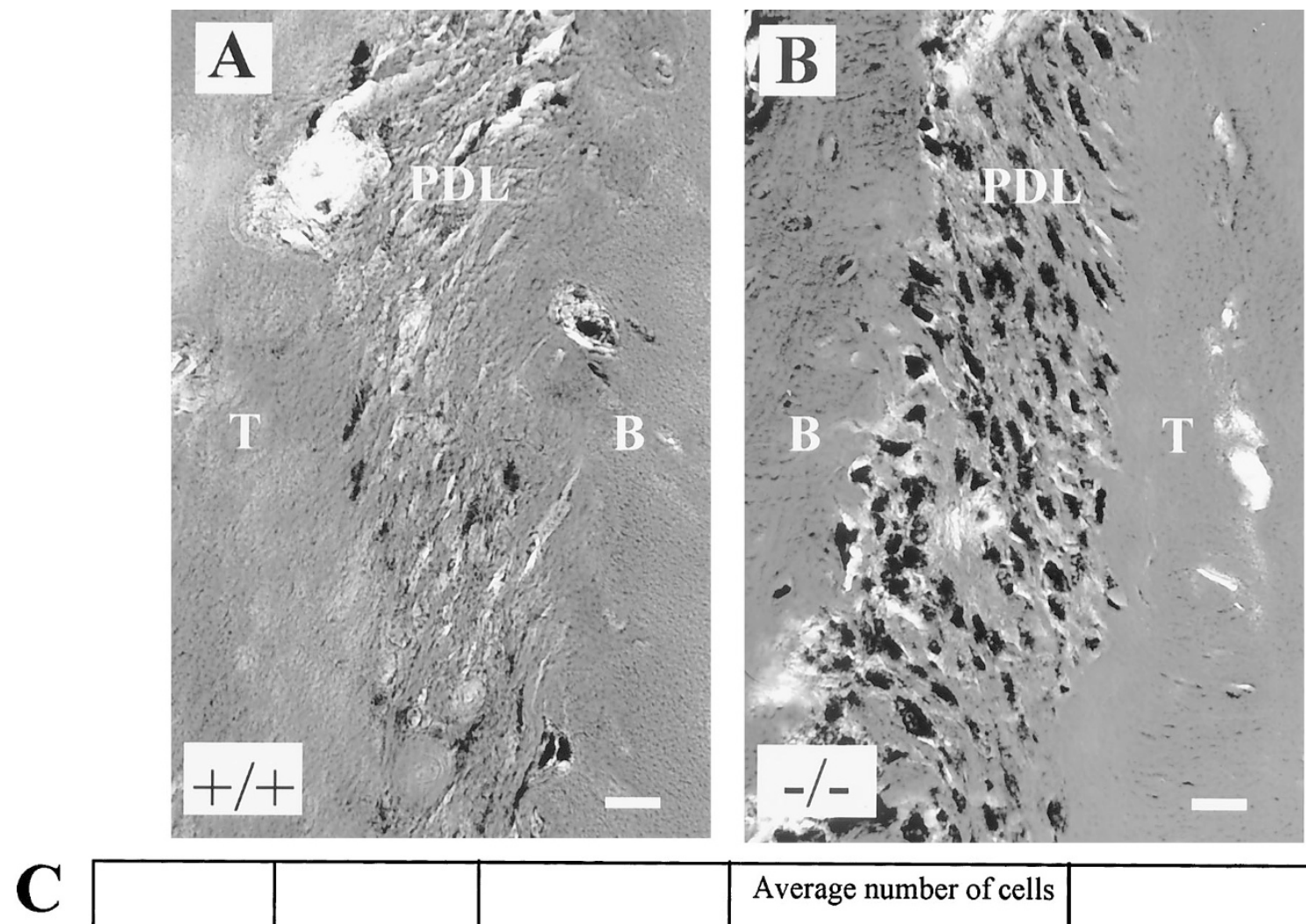

\begin{tabular}{|c|c|c|c|c|c|c|c|}
\hline Mouse Nr. & $\begin{array}{l}\text { Knockout -/- } \\
\text { Wild type +/+ }\end{array}$ & Age (months)/Sex & $\begin{array}{l}\text { Averag } \\
\text { per uni } \\
\text { period } \\
\text { MEAN }\end{array}$ & $\begin{array}{l}t \text { number } \\
t \text { area in the } \\
\text { ntal ligame } \\
+/ \text { SEM }\end{array}$ & $\begin{array}{l}\mathrm{f} \text { cells } \\
\mathrm{nt} \\
\mathrm{n} \\
\end{array}$ & MEAN +/-SEM & $\mathrm{n}$ \\
\hline 62 & $-/-$ & $3 / \mathrm{F}$ & 15.1 & $+/-0.7$ & 40 & \multirow{5}{*}{$\begin{array}{l}20.8 * * *+/-0.5 \\
(\mathrm{p}<0.0001)\end{array}$} & \multirow{5}{*}{209} \\
\hline 63 & $-/-$ & $3 / \mathrm{F}$ & 21.6 & $+/-1.2$ & 33 & & \\
\hline 177 & $-1-$ & $3 / \mathrm{M}$ & 20.4 & $+/-0.9$ & 56 & & \\
\hline 80 & $-/-$ & $5 / \mathrm{M}$ & 26.4 & $+/-1.2$ & 40 & & \\
\hline 18 & $-1-$ & $13 / F$ & 21.0 & $+/-0.8$ & 40 & & \\
\hline 61 & $+/+$ & $3 / \mathrm{M}$ & 13.3 & $+/-0.9$ & 39 & \multirow{5}{*}{11.0} & \multirow{5}{*}{209} \\
\hline 89 & $+/+$ & $3 / \mathrm{F}$ & 11.8 & $+/-0.4$ & 46 & & \\
\hline 178 & $+/+$ & $3 / \mathrm{M}$ & 16.1 & $+/-0.7$ & 40 & & \\
\hline 124 & $+/+$ & $8 / \mathrm{M}$ & 11.8 & $+/-0.6$ & 42 & & \\
\hline 17 & $+/+$ & $13 / F$ & 2.5 & $+/-0.3$ & 42 & & \\
\hline
\end{tabular}

Figure 3.

Analysis of cell numbers in the molar periodontal ligament. Periodontal ligament of decorin -/- mice is hypercellular $(B)$ compared with wild-type mice $(A)$. $C$, Histomorphometrical analysis of the number of fibroblasts in the periodontal ligament of decorin $-/$ - and wild-type mice (mean \pm SEM, Student's $t$ test). A total of 33 to 56 microscopic fields, each measuring $0.185 \mathrm{~mm}^{2}$, from each mouse was included in the calculations. B, Bone; PDL, periodontal ligament; $\mathrm{T}$, tooth. $A$ and $B$, Phosphotungstic acid hematoxylin staining; bar $=100 \mu \mathrm{m}$. 
culture, whereas clone DCN4 (3-fold-increased decorin expression) showed a strongly reduced proliferation rate (Fig. 4B). To test whether exogenous decorin could inhibit the growth of periodontal fibroblasts, we analyzed cell growth in the presence or absence of decorin. Decorin dose-dependently inhibited cell growth of human gingival and periodontal ligament fibroblasts (Fig. 4C). After 5 days, the increase in cell number in cultures treated with $50 \mu \mathrm{g} / \mathrm{ml}$ decorin was reduced by $17.4 \%$ to $46.5 \%$ compared

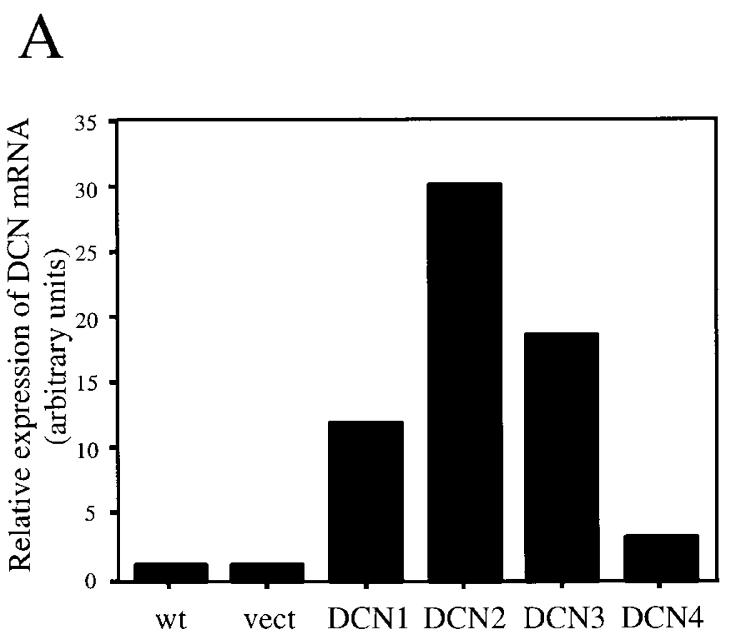

B

$\mathrm{C}$
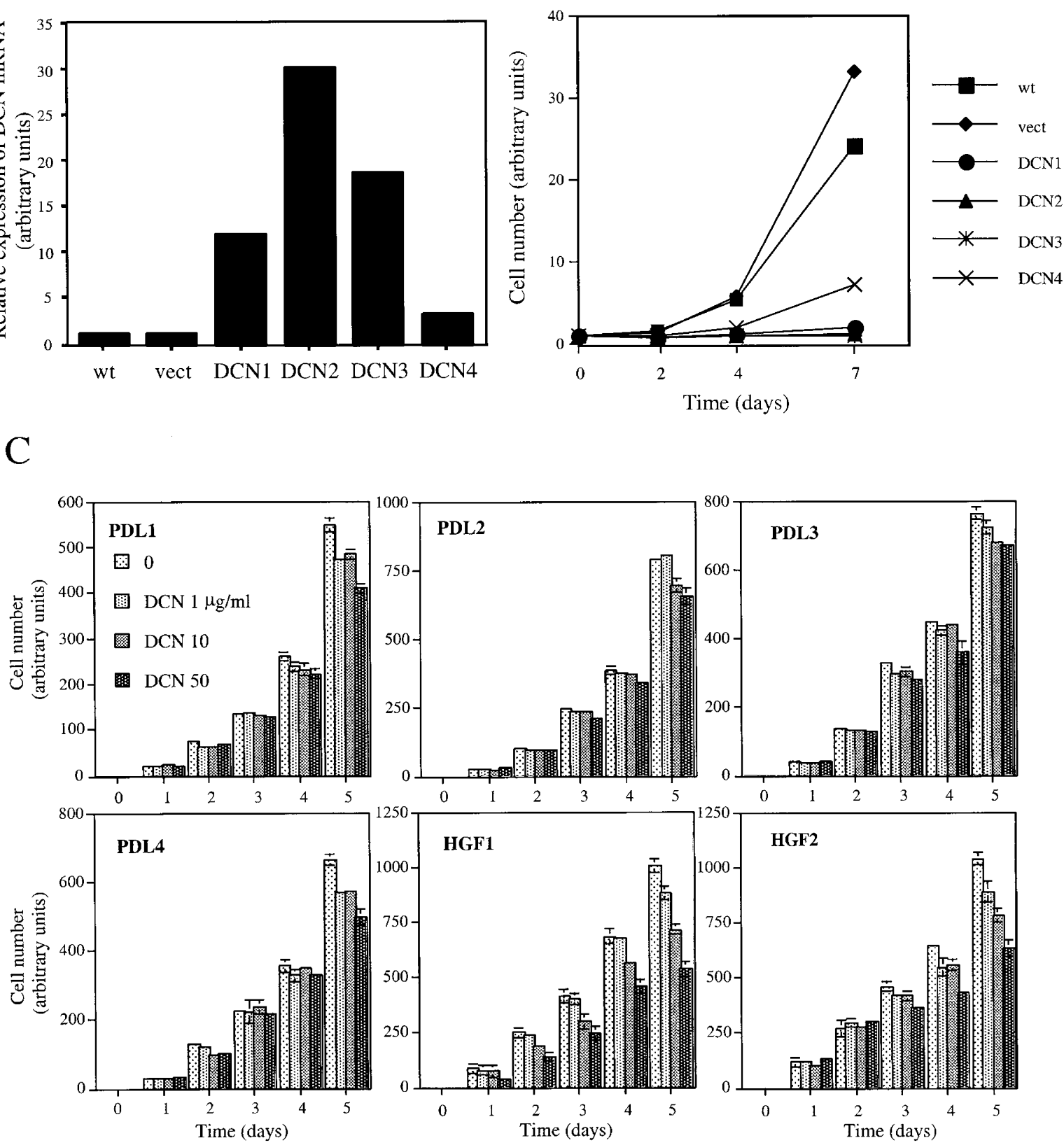

Figure 4.

Inhibition of cell growth by decorin. A, Quantitation of decorin mRNA expression in mouse NIH 3T3 cells stably transfected with human decorin cDNA. The relative levels of decorin mRNA were compared with the level of glyceraldehyde-3-phosphate dehydrogenase (GAPDH) mRNA in the same samples by densitometry of the autoradiographs. wt, wild-type cells; vect, cells transfected with the vector plasmid only; DCN1-4, cell clones transfected with the human decorin cDNA constructs. $B$, Analysis of cell growth by the cell clones stably overexpressing decorin. Equal numbers of cells were seeded in 96-well plates in triplicate at low density in DMEM containing $10 \% \mathrm{FBS}$, and the cell numbers were measured by using nonradioactive cell proliferation assay at the beginning of the experiment and thereafter, as indicated. Results show mean $\pm \mathrm{SD}$; standard deviations for all of the samples were smaller than 1.0 arbitrary unit and are not shown. $C$, Exogenous decorin dose-dependently inhibits growth of human gingival and periodontal ligament fibroblasts. Equal numbers of human periodontal ligament fibroblasts (PDL1, PDL2, PDL3, PDL4) or gingival fibroblasts (HGF1 and HGF2) were seeded into 96-well plates in triplicate at low density in DMEM containing 10\% FBS. After 4 hours, medium was replaced with a fresh medium, with or without bovine dermal decorin $(1-50 \mu \mathrm{g} / \mathrm{ml})$. Cells were allowed to proliferate up to 5 days, with medium change every other day. Cell count was determined as above. Results show mean \pm SD of triplicate wells; standard deviations smaller than 20.0 arbitrary units are not shown. 
with untreated cells (Fig. 4C). In a set of experiments, human gingival fibroblasts (HGF1) that showed the highest growth suppression were treated with or without 1 to $200 \mu \mathrm{g} / \mathrm{ml}$ decorin. After 5 days, the increase in cell number in cultures treated with $200 \mu \mathrm{g} / \mathrm{ml}$ decorin was maximally reduced by $57.0 \%$ compared with untreated cultures (data not shown). Cell cultures treated with corresponding molar amounts of decorin core protein or recombinant bovine decorin showed identical results as bovine dermal decorin in the cell growth assay (not shown).

In transformed cells, decorin elicits growth suppression by binding to an epidermal growth factor receptor (EGFR). This interaction induces phosphorylation of the EGFR that leads to activation of the mitogenactivated protein kinase (MAPK) pathway, upregulation of p21 cyclin-dependent kinase-inhibitor expression, and an increase in the intracellular $\mathrm{Ca}^{2+}$ level (De Luca et al, 1996; lozzo et al, 1999; Moscatello et al, 1998; Patel et al, 1998; Santra et al, 1997). To assess whether the phosphorylation of EGFR is critical for the growth inhibitory effect of decorin on normal periodontal fibroblasts (HGF1), we studied cell growth in the presence or absence of tyrphostin AG1478, a specific inhibitor of the EGFR tyrosine kinase (Levitzki and Gazit, 1995). Treatment with decorin alone (50 $\mu \mathrm{g} / \mathrm{ml}$ ) resulted in $62.5 \%$ and $52.8 \%$ reduction in cell growth compared with untreated cells after 2 and 3 days, respectively (Fig. 5A). Low concentrations of AG1478 alone did not markedly affect cell growth, whereas, in cultures treated with $6 \mu \mathrm{M}$ AG1478, cell growth was reduced by $21.3 \%$ and $10.7 \%$ after 2 and 3 days, respectively, compared with untreated cells (Fig. 5A). When cells were treated with different concentrations of AG1478 in combination with decorin, AG1478 did not alter the growth suppression induced by decorin (Fig. 5A). Then, using Northern hybridization, we analyzed the expression of p21 mRNA in periodontal fibroblasts (HGF1) treated with or without $50 \mu \mathrm{g} / \mathrm{ml}$ decorin. Results showed a relatively high basal expression level of p21 in the periodontal fibroblasts (Fig. 5B). When the cells were treated with decorin, they showed 1.2-fold increase in the relative expression of p21 mRNA compared with the untreated cells (Fig. 5B). Treatment of cells with $10 \%$ FBS or EGF $(100 \mathrm{ng} / \mathrm{ml})$ induced 1.4 and 1.2-fold increases, respectively, in the relative levels of p21 compared with untreated cells (Fig. 5B). When decorin (50 $\mu \mathrm{g} / \mathrm{ml})$ was added together with $10 \%$ FBS, it did not alter the relative expression level of p21 mRNA (Fig. 5B). The experiments were repeated several times with similar results.

\section{Discussion}

Development and differentiation of dental and periodontal tissues is characterized by spatially and temporally regulated deposition of different extracellular matrix components, including proteoglycans (Thesleff and Hurmerinta, 1981). During development, decorin is deposited in collagen type I-rich extracellular matrices including the soft connective tissues, periosteum, and pericellular matrices of many odontogenic cell types (Bianco et al, 1990; Matsuki et al, 1995; Yoshiba et al, 1996; Zhang et al, 1995). Decorin is also expressed in adult dental and periodontal tissues including dentin, root cementum, alveolar bone (Cheng et al, 1999a; Robey, 1996), periodontal ligament, and gingiva (Häkkinen et al, 1993). In dentin and bone, decorin localizes to the calcification zone, and there seems to be less decorin in the mineralized matrix (Hoshi et al, 1999; Zhang et al, 1995). In bone, removal of decorin from the matrix at the calcification zone colocalizes with lateral fusion of collagen fibrils that are becoming mineralized (Hoshi et al, 1999). Decorin retards the rate and degree of collagen fibrillogenesis in vitro (Vogel et al, 1984), an effect mediated by the decorin core protein that binds to collagen (Pogany and Vogel, 1992). Given the importance of decorin in the regulation of collagen fibril organization during fibril assembly, it would be expected that decorin deficiency could affect the development of the dental and periodontal tissues. In the decorin-deficient adult mice, the molar teeth were fully erupted and, like the alveolar bone, did not show any morphological abnormalities compared with the wild-type mice. However, the decorin-deficient mice showed abnormalities that were manifested in the soft connective tissue of the periodontal ligament, which showed abnormal collagen fibril morphology and organization as well as hypercellularity. The periodontal ligament collagen fibers were heterogeneous in size and irregular in shape, suggesting abnormal lateral fusion of the fibrils. Similar abnormal collagen fibrillogenesis has also been noted in the skin of the decorin-deficient mice (Danielson et al, 1997) and in the lumican knock-out mice (Chakravarti et al, 1998). The lack of well-defined collagen fibrils in the dermis and periodontal ligaments of these mice is reminiscent of human post-burn hypertrophic scar, which is also characterized by a deficiency of decorin (Scott et al, 1995, 1996). No abnormalities in the mineralized tissues of decorin knock-out mice have been reported. It is therefore possible that the role of decorin in the formation of the extracellular matrix of bone and teeth is not as important as in that of the soft connective tissues.

The collagen fibrils of the periodontal ligament are formed during tooth eruption and undergo reorganization to resist the strains from masticatory functions once the tooth is fully erupted and functional. In the adult periodontal ligament, the metabolic activity of cells and the turnover rate of collagen and cells are high compared with other tissues to rapidly adapt the ligament to the functional changes. Fibroblasts are the predominant cell type in the periodontal ligament, and they are responsible for the deposition and turnover of the ligament extracellular matrix. In the decorindeficient mice, the number of fibroblasts in the periodontal ligament was almost doubled compared with the wild-type animals. Ectopic overexpression of decorin in 3T3 cells or exogenous decorin in periodontal fibroblast cultures dose-dependently suppressed cell growth. This effect was mediated by the decorin core protein. These findings suggest that, in the 


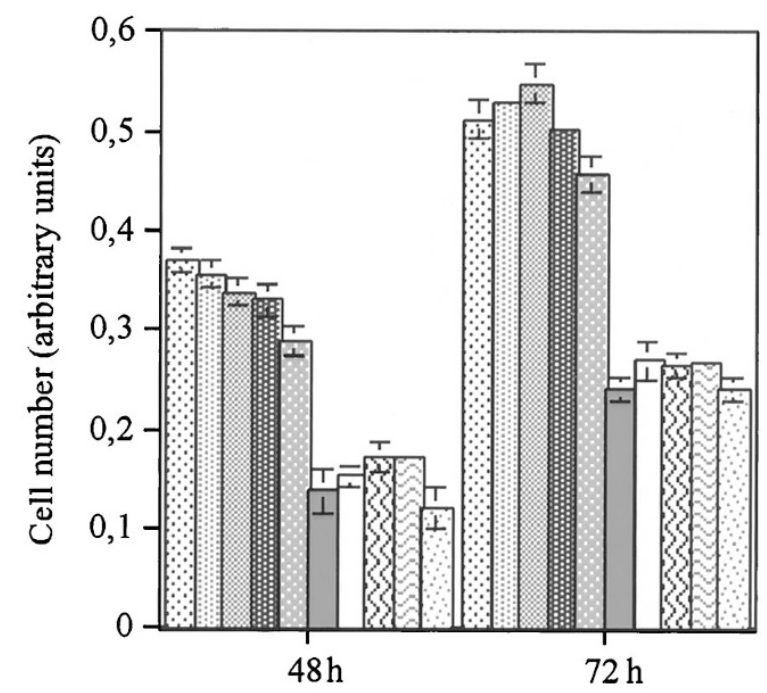

$\mathrm{AG} 1478(\mu \mathrm{M})-1246-1246-1246-1246$

Decorin $(50 \mu \mathrm{g} / \mathrm{ml})$ - - - - + + + + - - - + + + +

B

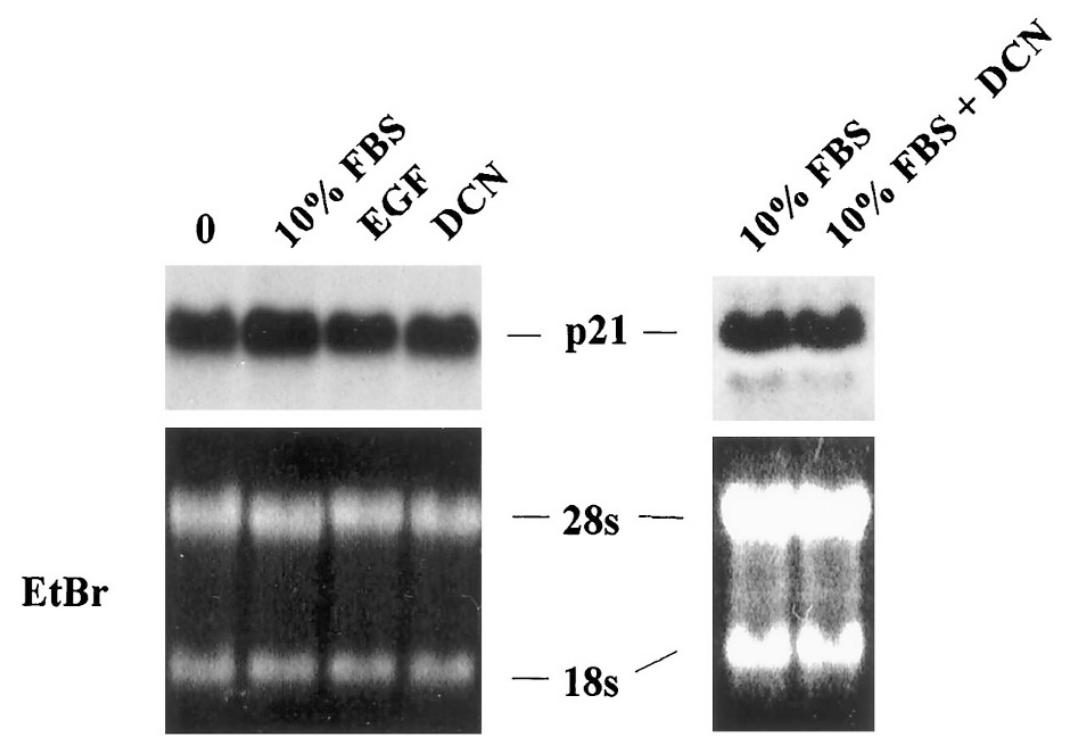

Figure 5.

A, Tyrphostin AG1478 does not prevent the suppression of cell growth by exogenous decorin in human periodontal fibroblasts. Equal number of cells (HGF1) were seeded into 96 -well plates in triplicate at low density in DMEM containing $10 \%$ FBS. After 4 hours, medium was replaced with fresh medium, with or without bovine dermal decorin $(50 \mu \mathrm{g} / \mathrm{ml})$ and $/$ or tyrphostin $(1-6 \mu \mathrm{M})$. Cells were allowed to proliferate up to 3 days with medium change daily. Cell number was determined at the beginning of the assay and as indicated. Results show mean \pm SD of triplicate wells; standard deviations smaller than 0.02 arbitrary units are not shown. $B$, Effect of exogenous decorin on p21 mRNA expression by human periodontal fibroblasts. Fibroblasts (HGF1) were serum starved for 24 hours and then cultured with or without $10 \%$ FBS, EGF $(100 \mathrm{ng} / \mathrm{ml})$, or bovine dermal decorin $(50 \mu \mathrm{g} / \mathrm{ml})$, or $10 \%$ FBS and decorin $(50 \mu \mathrm{g} / \mathrm{ml})$ for 48 hours. After Northern blotting, the relative levels of p21 mRNA were compared with the level of rRNA in the same samples by densitometry.

decorin-deficient mice, hypercellularity of the periodontal ligament may result from increased proliferation of fibroblasts during development and/or tissue maintenance because of a lack of inhibitory signals from decorin. We hypothesize that the high turnover rate of the cells in the periodontal ligament may increase the effect of decorin deficiency on the cell proliferation. In gingival hyperplasia, hypercellularity of the connective tissue is also associated with increased accumulation of extracellular matrix (Hassell et al, 1978). However, in the present study, we did not detect any differences in the amount of extracellular matrix in the periodontal ligament of the decorindeficient and wild-type mice. We cannot, however, completely rule out the possibility that hypercellularity may have some effect on the amount of extracellular matrix deposited in the periodontal ligament.

Ectopic decorin expression or the addition of exogenous decorin or its core protein can suppress the growth of neoplastic cells of various histiogenic ori- 
gins (Santra et al, 1997). This is caused by rapid phosphorylation of the EGFR and the subsequent activation of the MAPK signaling pathway and induction of endogenous p21 production, leading to cellcycle arrest (Moscatello et al, 1998). Decorin also causes an increase in the level of intracellular $\mathrm{Ca}^{2+}$ in A431 colon carcinoma cells (Patel et al, 1998). These effects of decorin can be blocked by tyrphostin AG1478, a specific EGFR tyrosine-kinase inhibitor, and by down-regulating EGFR (Moscatello et al, 1998; Santra et al, 1997). When human periodontal fibroblasts were cultured in the presence of exogenous decorin together with AG1478, there was no change in the cell-growth suppression induced by decorin. Additionally, when fibroblasts were cultured in the presence or absence of decorin, there was only a minor increase in the relative levels of p21 mRNA. If fibroblasts were cultured in the presence of $10 \%$ FBS, the relative level of $\mathrm{p} 21 \mathrm{mRNA}$ was up-regulated, but it was unaffected by exogenous decorin, although in this condition decorin potently suppressed the growth of these cells. In fibroblasts, p21 can be induced in addition to serum by various growth factors, including fibroblast growth factor (FGF)-2, platelet-derived growth factor (PDGF), and TGF- $\beta 1$, which are mitogens for these cells (Kivinen and Laiho, 1999). Therefore, it seems that the function of p21 in normal diploid fibroblasts differs from its function in neoplastic cells. In fibroblasts, p21 seems to be necessary for certain processes that positively regulate cell proliferation (Cheng et al, 1999b). Taken together, the findings in this study suggest that in normal periodontal fibroblasts the mechanism of cell growth suppression by decorin is different from that in neoplastic cells and remains to be elucidated in the future studies.

Many connective tissue disorders have been associated with aberrant collagen fibril organization and morphology (Kuivaniemi et al, 1991). Although glycoproteins and proteoglycans regulate collagen fibrillogenesis, it is not known whether these disorders also involve defects in molecules other than collagen. Interestingly, EDS types IV, VII, VIII, and IX, which involve defective collagen fibrillogenesis as one of their main characteristics, are also associated with early onset periodontal disease (Aldred and Bartold, 1998; Fushimi et al, 1989; Hartsfield and Kousseff, 1990; Ooshima et al, 1990). In EDS type IV, the basic defect seems to be mutations in the COL3A1 gene, whereas EDS type VII involves mutations in COL1A1 or COL1A2 genes. The genetic background of EDS types XVIII and IX is largely unknown (Pope and Burrows, 1997). The phenotypes of decorin (Danielson et al, 1997) and lumican (Chakravarti et al, 1998) gene knock-out mice suggest that abnormal expression of proteoglycans may actually be a primary cause of some of these conditions. Interestingly, one study has reported that, in a patient suffering from an EDS variant with a single adrenocorticotrophic hormone deficiency and mild diabetes, the deposition of decorin in the skin was markedly reduced because of defective decorin core protein synthesis by fibroblasts (Fushimi et al, 1989). In skin, the lack of decorin leads to functional deficiency, characterized by skin fragility when the skin is stretched (Danielson et al, 1997). There were no clear functional abnormalities in the teeth of the decorin-deficient mice because the mice grew normally, which suggests that they were able to eat normally (Danielson et al, 1997). Additionally, the mice did not show any signs of periodontal disease. The prerequisite for periodontal disease is an initial bacterial challenge that causes inflammation of the periodontal tissues. It is likely that if the connective tissue matrix of the periodontal tissues is defective, then its ability to resist microbial-induced inflammation or repair inflammatory-mediated damage would be significantly compromised and lead to increased tissue breakdown. Therefore, it is possible that aberrant collagen organization because of decorin deficiency may lead to increased susceptibility to periodontal disease. Natural periodontal disease in laboratory mice is extremely rare (Page and Schroeder, 1982). Therefore, it is not likely that decorin deficiency would lead to increased susceptibility of the mice to the periodontal disease unless the mice are exposed to experimentally induced periodontal disease.

\section{Materials and Methods}

\section{Decorin-Deficient Mice, Histochemical and Immunohistochemical Staining, Scanning and Transmission Electron Microscopy, and Histomorphometrical Analysis}

The generation and characterization of the decorin -/mice has been previously described in detail elsewhere (Danielson et al, 1997). Five decorin -/- mice (ages 3 to 13 months) and their age- and sex-matched wild-type littermates were killed and fixed immediately in $10 \%$ neutral buffered formalin. Jaws and teeth were visually inspected, photographed, and radiographed before dissecting the jaws containing intact periodontal tissues and teeth to separate maxilla and mandible. The jaws were decalcified in 5\% formic acid containing $0.9 \% \mathrm{NaCl}$, embedded in paraffin, and processed for sectioning. Mesiodistal plane sections $(5 \mu \mathrm{m})$ were deparaffinized and stained with hematoxylin and eosin or Movats pentachrome stain (Schmidt and Wirtala, 1996) to characterize the gross morphology of the tissues.

For immunohistochemical localization of decorin and biglycan, deparaffinized sections of mandibular molar and incisor periodontal tissues were incubated in $0.3 \%$ hydrogen peroxide in methanol for $30 \mathrm{~min}-$ utes. Sections were rinsed and incubated with normal blocking serum (Vectastain; Vector Laboratories Inc., Burlingame, California) for 60 minutes at room temperature and then incubated with rabbit polyclonal antibody against decorin (LF-113) or biglycan (LF-106) (gifts from Dr. Larry Fisher, National Institutes of Health, MIDR, Bethesda, Maryland) at $4^{\circ} \mathrm{C}$ for 16 hours. After rinsing, sections were incubated with biotinylated antirabbit antibody for 60 minutes and then reacted with $A B C$ avidin/peroxidase reagent (Vectastain Elite kit, Vector Laboratories Inc.). Chro- 
mogen was developed using diaminobenzidine (DAB; Chemicon, Temecula, California). The sections were briefly counterstained with hematoxylin before mounting in Permount (Fisher Scientific, Pittsburgh, Pennsylvania).

For immunohistochemical localization of type I collagen, deparaffinized sections of mandibular molar periodontal tissues were treated with $0.1 \%$ pepsin for 2 hours at $37^{\circ} \mathrm{C}$, and then rinsed and incubated with a rabbit antihuman type I collagen antibody (Quartett Immunodiagnostica und Biotechnologie $\mathrm{GmbH}$, Berlin, Germany). After rinsing, sections were treated with rabbit antimouse IgG (diluted 1:70) (Dako, Glostrup, Denmark) and then with the mouse APAAP complex (Dako). All incubations were carried out for 30 minutes at room temperature. Naphtol-AS-biphosphate (Sigma, St. Louis, Missouri) and new fuchsin (Merck, Darmstadt, Germany) were used as substrate and developer, respectively. To inhibit endogenous tissue enzyme activity, the developing solution was supplemented with $0.25 \mathrm{mmol} / \mathrm{l}$ levamisole (Sigma). After color development, the sections were counterstained briefly with hematoxylin and mounted in glycerol gelatin (Serva, Heidelberg, Germany).

Portions of periodontal ligament, alveolar bone, and dentin at the mid-root area of maxillary molars from decorin -/- and wild-type mice were microdissected from the paraffin-embedded tissue blocks and processed for transmission electron microscopy (Dawes, 1981). Thin sections were examined and photographed using a Phillips 300 transmission electron microscope. For scanning electron microscopy, paraffin sections from the mid-root region of the periodontal ligament of maxillary or mandibular molars were processed using standard procedures (Postek et al, 1980) and examined using a Cambridge 260 Stereoscan scanning electron microscope.

For histomorphometrical analysis, paraffin sections from decorin -/- and wild-type mice were stained with phosphotungstic acid hematoxylin (Puchtler et al, 1963) and the mid-third area of the periodontal ligament of the mandibular molars was photographed using a light microscope equipped with a $\times 20$ lens. The number of fibroblasts was quantitated by counting cells with spindle-shaped morphology and located in the periodontal ligament. Cell numbers in a total of 33 to 56 areas (each measuring $0.185 \mathrm{~mm}^{2}$ ) from the periodontal ligament from each mouse were calculated.

\section{cDNA Transfection, Proliferation Assay, and Northern Blotting}

The coding region of human decorin cDNA was cloned into expression vector SG5 (Stratagene, Heidelberg, Germany) under the control of SV promoter. Mouse NIH 3T3 fibroblasts were stably cotransfected, either with decorin expression construct or with the empty expression vector in combination with pBGS(neo)
(Takebe et al, 1988), using the calcium phosphate precipitation method (Chen and Okayama, 1987). Neomycin-resistant clones were selected in the presence of G418 $(500 \mu \mathrm{g} / \mathrm{ml})$ and maintained in Dulbecco's modified Eagles medium (DMEM) containing $10 \%$ fetal bovine serum (FBS) and G418 (250 $\mu \mathrm{g} / \mathrm{ml})$. The expression of human decorin by the cell clones was studied by Northern blot hybridizations (see below).

To determine growth, NIH 3T3 cells stably overexpressing decorin, their vector and wild-type controls, and fibroblasts from two healthy human gingival (HGF1 and HGF2) and four periodontal ligament (PDL1-4) fibroblast strains (Häkkinen et al, 1996) were serum-starved for 24 hours and then seeded at low density (5000 cells/well) into 96 -well microtiter plates in triplicate in DMEM containing $10 \%$ FBS. Human fibroblasts were allowed to attach for 4 hours, and the medium was then replaced with either fresh medium with or without bovine dermal decorin (0 to $200 \mu \mathrm{g} / \mathrm{ml}$ ) (Pearson et al, 1983) or an equal molar amount of decorin core protein (prepared by digestion with chondroitin ABC lyase) (Pearson et al, 1983) or fully glycosylated recombinant bovine decorin ( 0 and $50 \mu \mathrm{g} / \mathrm{ml}$ ) (manuscript in preparation). Cells were allowed to proliferate up to 7 days during which time the medium was changed every other day. The cell count was determined after 4 hours and every 24 hours thereafter by using nonradioactive cell proliferation assay (CellTiter96 ${ }^{\mathrm{TM}}$ kit; Promega, Madison, Wisconsin). In one set of experiments, human gingival fibroblasts were treated with or without bovine dermal decorin and 0 to $6 \mu \mathrm{m}$ tyrphostin (AG1478, Sigma), with daily medium change, and cell growth was analyzed as above.

For Northern blotting of decorin, the NIH 3T3 cell lines stably transfected with decorin cDNA, vector controls, and wild-type cells were cultured in DMEM containing 1\% FBS and antibiotics for 24 hours. For Northern blotting of p21WAF1/C1P1 cyclin-dependent kinase inhibitor, human gingival fibroblasts were cultured in DMEM containing $10 \%$ FBS to $75 \%$ confluence and then serum-starved for 24 hours. Fibroblasts were then cultured in DMEM with or without bovine decorin $(50 \mu \mathrm{g} / \mathrm{ml})$, recombinant human EGF (100 $\mathrm{ng} / \mathrm{ml}$ ) (GIBCO BRL, Gaithersburg, Maryland), or 10\% FBS or decorin $(50 \mu \mathrm{g} / \mathrm{ml})$, together with $10 \%$ FBS for 48 hours. Total RNA was isolated using RNeasy Kit (Qiagen, Hilden, Germany) and electrophoresed (15 $\mu \mathrm{g} /$ lane) in formaldehyde $/ 1 \%$ agarose gel, blotted onto a nylon membrane (Zeta-Probe; Bio-Rad, Hercules, California), and hybridized with ${ }^{32} \mathrm{P}$-random primed (Random Primed DNA Labeling Kit; Boehringer, Mannheim, Germany) full-length human decorin (Krusius and Ruoslahti, 1986) or p21 WAF1/C1P1 (el-Deiry et al, 1994) cDNA. The levels of decorin and p21 mRNA were determined by densitometry of the autoradiographs and normalized against either glyceraldehyde-3phosphate dehydrogenase (GAPDH) mRNA or rRNA, respectively, stained with ethidium bromide. 


\section{Acknowledgements}

We thank Dr. L. Fisher, NIH, Bethesda, Maryland, and Dr. W. el-Deiry, Howard Hughes Medical Institute, Philadelphia, Pennsylvania, for providing valuable reagents.

\section{References}

Aldred MJ and Bartold PM (1998). Genetic disorders of the gingivae and periodontium. Periodontol 2000 18:7-20.

Beavan L, Quentin-Hoffmann E, Schonherr E, Snigula F, Leroy JG, and Kresse (1993). Deficient expression of decorin in infantile progeroid patients. J Biol Chem 268:9856-9862.

Beck JD, Pankow J, Tyroler HA, and Offenbacher S (1999). Dental infections and atherosclerosis. Am Heart J 138:528533.

Bianco P, Fisher LW, Young MF, Termine JD, and Robey PG (1990). Expression and localization of the two small proteoglycans biglycan and decorin in developing human skeletal and non-skeletal tissues. J Histochem Cytochem 38:15491563.

Border WA, Noble NA, Yamamoto T, Harper JR, Yamaguchi Y, Pierschbacher MD, and Ruoslahti E (1992). Natural inhibitor of transforming growth factor-beta protects against scarring in experimental kidney disease. Nature 360:361-364.

Brown L and Loe H (1993). Prevalence, extent, severity and progression of periodontal disease. Periodontol 2000 2:5771.

Chakravarti S, Magnuson T, Lass JH, Jepsen KJ, LaMantia C, and Carroll H (1998). Lumican regulates collagen fibril assembly: Skin fragility and corneal opacity in the absence of lumican. J Cell Biol 141:1277-1286.

Chen C and Okayama H (1987). High-efficiency transformation of mammalian cells by plasmid DNA. Mol Cell Biol 7:2745-2752.

Cheng H, Caterson B, and Yamauchi M. (1999a). Identification and immunolocalization of chondroitin sulfate proteoglycans in tooth cementum. Connect Tissue Res 40:37-47.

Cheng M, Olivier P, Diehl JA, Fero M, Roussel MF, Roberts JM, and Sherr CJ. (1999b). The p21(Cip1) and p27(Kip1) CDK "inhibitors" are essential activators of cyclin D-dependent kinases in murine fibroblasts. EMBO J 18:1571-1583.

Danielson KG, Baribault H, Holmes DF, Graham H, Kadler KE, and lozzo RV (1997). Targeted disruption of decorin leads to abnormal collagen fibril morphology and skin fragility. J Cell Biol 136:729-743.

Dawes CJ (1981). Biological techniques for transmission and scanning electron microscopy. Burlington: Ladd Research Industries, Inc., 303 pp.

De Luca A, Santra M, Baldi A, Giordano A, and lozzo RV (1996). Decorin-induced growth suppression is associated with up-regulation of p21, an inhibitor of cyclin-dependent kinases. J Biol Chem 271:18961-18965.

el-Deiry WS, Harper JW, O'Connor PM, Velculescu VE, Canman CE, Jackman J, Pietenpol JA, Burrell M, Hill DE, Wang Y, Wiman KG, Mercer WE, Kastan MB, Kohn KW, Elledge SJ, Kinzler KW, and Vogelstein B (1994). WAF1/CIP1 is induced in p53-mediated G1 arrest and apoptosis. Cancer Res 54:1169-1174.
Fedarko NS, Moerike M, Brenner R, Robey PG, and Vetter U (1992). Extracellular matrix formation by osteoblasts from patients with osteogenesis imperfecta. J Bone Miner Res 921-930.

Fushimi H, Kameyama M, and Shinkai H (1989). Deficiency of the core proteins of dermatan sulphate proteoglycans in a variant form of Ehlers-Danlos syndrome. J Intern Med 226: 409-416.

Giri SN, Hyde DM, Braun RK, Gaarde W, Harper JR, and Pierschbacher MD (1997). Antifibrotic effect of decorin in a bleomycin hamster model of lung fibrosis. Biochem Pharmacol 54:1205-1216.

Häkkinen L, Oksala O, Salo T, Rahemtulla F, and Larjava H (1993). Immunohistochemical localization of proteoglycans in human periodontium. J Histochem Cytochem 41:16891699.

Häkkinen L, Westermarck J, Kähäri V-M, and Larjava H (1996). Human granulation-tissue fibroblasts show enhanced proteoglycan gene expression and altered response to TGFbeta 1. J Dent Res 75:1767-1778.

Hassell TM, Page RC, and Lindhe J (1978). Histologic evidence for impaired growth control in diphenylhydantoin gingival overgrowth in man. Arch Oral Biol 23:381-384.

Hart TC, Hart PS, Michalec MD, Zhang Y, Marazita ML, Cooper M, Yassin OM, Nusier M, and Walker S (2000). Localization of a gene for prepubertal periodontitis to chromosome 11q14 and identification of a cathepsin $C$ gene mutation. J Med Genet 37:95-101.

Hartsfield JK Jr and Kousseff BG (1990). Phenotypic overlap of Ehlers-Danlos syndrome types IV and VIII. Am J Med Genet 37:465-470.

Hoshi K, Kemmotsu S, Takeuchi Y, Amizuka N, and Ozawa H (1999). The primary calcification in bones follows removal of decorin and fusion of collagen fibrils. $J$ Bone Miner Res 14:273-280.

lozzo RV (1998). Matrix proteoglycans: From molecular design to cellular function. Annu Rev Biochem 67:609-652.

lozzo RV (1999). The biology of the small leucine-rich proteoglycans: Functional network of interactive proteins. J Biol Chem 274:18843-18846.

lozzo RV, Moscatello DK, McQuillan DJ, and Eichstetter I (1999). Decorin is a biological ligand for the epidermal growth factor receptor. J Biol Chem 274:4489-4492.

Kähäri V-M, Larjava H, and Uitto J (1991). Differential regulation of extracellular matrix proteoglycan (PG) gene expression: Transforming growth factor- $\beta 1$ upregulates biglycan (PG I), and versican (large fibroblast PG) but downregulates decorin (PG II) mRNA levels in human fibroblasts in culture. J Biol Chem 266:10608-10615.

Kivinen L and Laiho M (1999). Ras- and mitogen-activated protein kinase kinase-dependent and -independent pathways in p21Cip1/Waf1 induction by fibroblast growth factor-2, platelet-derived growth factor, and transforming growth factor-beta1. Cell Growth Differ 10:621-628.

Krusius T and Ruoslahti E (1986). Primary structure of an extracellular matrix proteoglycan core protein deduced from cloned cDNA. Proc Natl Acad Sci USA 83:7683-7687.

Kuivaniemi H, Tromp G, and Prockop D (1991). Mutations in collagen genes: Causes of rare and some common diseases in humans. FASEB J 5:2052-2060. 
Laine P, Reunanen N, Ravanti L, Foschi M, Santra M, lozzo RV, and Kähäri V-M (2000). Activation of extracellular signalregulated kinase1,2 results in down-regulation of decorin expression in fibroblasts. Biochem J 349:19-25.

Larjava H, Häkkinen L, and Rahemtulla F (1992). A biochemical analysis of human periodontal tissue proteoglycans. Biochem J 284:267-274.

Levitzki A and Gazit A (1995). Tyrosine kinase inhibition: An approach to drug development. Science 267:1782-1788.

Matsuki Y, Nakashima M, Amizuka N, Warshawsky H, Goltzman D, Yamada KM, and Yamada Y (1995). A compilation of partial sequences of randomly selected cDNA clones from the rat incisor. J Dent Res 74:307-312.

Mauviel A, Santra M, Chen YQ, Uitto J, and lozzo RV (1995). Transcriptional regulation of decorin gene expression. Induction by quiescence and repression by tumor necrosis factoralpha. J Biol Chem 270:11692-11700.

Moscatello DK, Santra M, Mann DM, McQuillan DJ, Wong AJ, and lozzo RV (1998). Decorin suppresses tumor cell growth by activating the epidermal growth factor receptor. J Clin Invest 101:406-412.

Nelson JA and Bartold PM (1998). Genetic disorders of the gingivae and periodontium. Periodontol 2000 18:7-20.

Oksala O, Haapasalmi K, Häkkinen L, Uitto VJ, and Larjava H (1997). Expression of heparan sulphate and small dermatan/ chondroitin sulphate proteoglycans in chronically inflamed human periodontium. J Dent Res 76:1250-1259.

Oksala O, Salo T, Tammi R, Häkkinen L, Jalkanen M, Inki P, and Larjava $H$ (1995). Expression of proteoglycans and hyaluronan during wound healing. $\mathrm{J}$ Histochem Cytochem 43:125-135.

Ooshima T, Abe K, Kohno H, Izumitani A, and Sobue $\mathrm{S}$ (1990). Oral manifestations of Ehlers-Danlos syndrome type VII: Histological examination of a primary tooth. Pediatr Dent 12:102-106.

Page R (1999). Milestones in periodontal research and the remaining critical issues. J Periodont Res 34:331-339.

Page RC and Schroeder HE (1982). Periodontitis in man and other animals. New York: Karger. 418 pp.

Patel S, Santra M, McQuillan DJ, lozzo RV, and Thomas AP (1998). Decorin activates the epidermal growth factor receptor and elevates cytosolic $\mathrm{Ca} 2+$ in A431 carcinoma cells. J Biol Chem 1273:3121-3124.

Pearson $\mathrm{CH}$, Winterbottom N, Fackre DS, and Scott PG (1983). The amino-terminal amino acid sequence of bovine skin proteodermatan sulfate. J Biol Chem 258:15101-15104.

Pogany G and Vogel KG (1992). The interaction of decorin core protein fragments with type I collagen. Biochem Biophys Res Commun 189:165-172.

Pope FM, Komorowska A, Lee KW, Speight P, Zorawska H, Ranta H, Coonar HS, and MacKenzie JL (1992). EhlersDanlos syndrome type I with novel dental features. J Oral Pathol Med 21:418-421.

Pope FM and Burrows NP (1997). Ehlers-Danlos syndrome has varied molecular mechanisms. J Med Genet 34:400410.

Postek MT, Howard KS, Johnson AH, and McMichael KL (1980). Scanning electron microscopy: A students handbook. Burlington: Ladd Research Industries, Inc. 305 pp.
Puchtler H, Sweat F, and Doss NO (1963). A one-hour phosphotungstic acid hematoxylin stain. Am J Clin Pathol 40:334-337.

Robey PG (1996). Vertebrate mineralized matrix proteins: Structure and function. Connect Tissue Res 35:131-136.

Santra M, Mann DM, Mercer EW, Skorski T, Calabretta B, and lozzo RV (1997). Ectopic expression of decorin protein core causes a generalized growth suppression in neoplastic cells of various histogenetic origin and requires endogenous p21, an inhibitor of cyclin-dependent kinases. J Clin Invest 100:149-157.

Santra M, Skorski T, Calabretta B, Lattime EC, and lozzo RV (1995). De novo decorin gene expression suppresses the malignant phenotype in human colon cancer cells. Proc Natl Acad Sci USA 92:7016-7020.

Schmidt R and Wirtala J (1996). Modification of Movat pentachrome stain with improved reliability of elastin staining. J Histotechnol 19:325-327.

Scott PG, Dodd CM, Tredget EE, Ghahary A, and Rahemtulla $F$ (1995). Immunohistochemical localization of the proteoglycans decorin, biglycan and versican and transforming growth factor- $\beta$ in human post-burn hypertrophic and mature scars. Histopathology 26:423-431.

Scott PG, Dodd CM, Tredget EE, Ghahary A, and Rahemtulla $F$ (1996). Chemical characterization and quantification of proteoglycans in human post-burn hypertrophic and mature scars. Clin Sci 90:417-425.

Takebe Y, Seiki M, Fujisawa J, Hoy P, Yokota K, Arai K, Yoshida M, and Arai N (1988). SR alpha promoter: An efficient and versatile mammalian cDNA expression system composed of the simian virus 40 early promoter and the R-U5 segment of human T-cell leukemia virus type 1 long terminal repeat. Mol Cell Biol 8:466-472.

Thesleff I and Hurmerinta K (1981). Tissue interactions in tooth development. Differentiation 18:75-88.

Trask BC, Trask TM, Broekelmann T, and Mecham RP (2000). The microfibrillar proteins MAGP-1 and fibrillin-1 form a ternary complex with the chondroitin sulfate proteoglycan decorin. Mol Biol Cell 11:1499-1507.

Vogel KG, Paulsson M, and Heinegard D (1984). Specific inhibition of type I and type II collagen fibrillogenesis by the small proteoglycan of tendon. Biochem J 223:587-597.

Waddington RJ, Embery G, and Smith AJ (1998). Immunochemical detection of the proteoglycans decorin and biglycan in human gingival crevicular fluid from sites of advanced periodontitis. Arch Oral Biol 43:287-295.

Yoshiba N, Yoshiba K, Iwaku M, and Ozawa H (1996). Immunolocalization of the small proteoglycan decorin in human teeth. Arch Oral Biol 41:351-357.

Yu QX and Zeng LH (1991). Progeria: Report of a case and review of the literature. J Oral Pathol Med 20:86-88.

Zhang CZ, Li H, Bartold PM, Young WG, and Waters MJ (1995). Effect of growth hormone on the distribution of decorin and biglycan during odontogenesis in the rat incisor. J Dent Res 74:1636-1643. 